\title{
Clinical importance of persistence of anticardiolipin antibodies in systemic lupus erythematosus
}

\author{
Y Ishii, K Nagasawa, T Mayumi, Y Niho
}

\begin{abstract}
The clinical importance of IgG anticardiolipin antibodies was investigated in systemic lupus erythematosus (SLE). IgG anticardiolipin antibodies were found in 69 of $155(44.5 \%)$ patients with SLE. Serial measurements of IgG anticardiolipin antibodies allowed the patients to be classified into two groups: group $A$, persistently positive for IgG anticardiolipin antibodies; group B, positive only in active phases. The IgG anticardiolipin antibody titre in group $A$ was significantly higher than in group B. The incidence of thromboses, spontaneous abortions, and lupus anticoagulant in group $A$ was significantly higher than in group $B(p<0.05)$. By contrast, the incidence of renal diseases and anti-dsDNA antibodies in group $B$ was significantly higher than in group $\mathbf{A}(\mathbf{p}<\mathbf{0} \cdot 05)$. This study showed that group A formed a separate subgroup of patients with SLE who had a high risk of thromboses and spontaneous abortions despite having milder disease activity.
\end{abstract}

Antiphospholipid antibodies, such as anticardiolipin antibodies and lupus anticoagulant, have recently been thought to be associated with the genesis of thrombosis, thrombocytopenia, pulmonary hypertension and spontaneous abortion in cases of systemic lupus erythematosus (SLE).$^{1-8}$ The measurement of IgG anticardiolipin antibodies seems to be the most predictive and specific test for thrombosis, recurrent fetal loss, and thrombocytopenia. ${ }^{9} \mathrm{~A}$ new subset of patients with SLE, the anticardiolipin syndrome, has been proposed by Hughes et al. ${ }^{10}$ Serial changes in anticardiolipin antibodies and their relation to clinical aspects, however, are not well understood. ${ }^{11}{ }^{12}$ The therapeutic effect of corticosteroids or immunosuppressants on anticardiolipin antibodies is also controversial. ${ }^{13-15}$ These factors prompted us to investigate the changes in anticardiolipin antibodies in association with the disease activity and clinical

The First Department of Internal Medicine, Faculty of Medicine, Kyushu University, 3-1-1, Maidashi, Higashi-ku, Fukuoka 812, Japan Y Ishii

K Nagasawa

T Mayumi

Y Niho

Correspondence to:

Dr K Nagasawa.

Accepted for publication

18 August 1989 features of SLE.

\section{Patients and methods}

Serum samples from 155 patients with SLE (10 men and 145 women, mean age 34 years, ranging from 14 to 62 years), which had been stored at $-80^{\circ} \mathrm{C}$, were used for the measurement of IgG anticardiolipin antibodies. Of 155 patients, 80 were at the active and 75 at stable stages, based on the activity score mentioned below. All patients with SLE satisfied the classification criteria of the American Rheumatism Association (ARA) for SLE. ${ }^{16}$

The patients were considered to be in active phases of SLE if they had at least three of the following abnormalities: (i) fever with no apparent infective cause; (ii) serositis; (iii) recent skin lesions or exacerbation of ald ones; (iv) recent onset or acceleration of alopecia or oral ulcers; (v) active central nervous system disease; (vi) increasing lymphadenopathy; (vii) leucopenia of less than $4 \times 10^{9} / 1$; (viii) erythrocyte sedimentation rate (ESR) exceeding $30 \mathrm{~mm} / \mathrm{first}$ hour; (ix) total haemolytic complement $\left(\mathrm{CH}_{50}\right)$ of lower than $20 \mathrm{U} / \mathrm{ml}$; (x) features of active nephritis.

\section{ENZYME IMMUNOASSAY OF IgG ANTICARDIOLIPIN} ANTIBODIES

Cardiolipin (Sigma Chemical Company, St Louis, Missouri, USA) was supplied in ethanol solution. Micelles were created in phosphate buffered saline (PBS) (pH 7•4) by sonication.

Serum IgG anticardiolipin antibodies were measured by an enzyme linked immunosorbent assay (ELISA) according to the procedure described by Koike et al, ${ }^{17}$ with some minor modifications. Briefly, each well of microtitre plates (Falcon, Oxnard, California, USA) was first coated with $50 \mu \mathrm{l}$ of cardiolipin solution at a concentration of $200 \mu \mathrm{g} / \mathrm{ml}$ in $0.01 \mathrm{M} \mathrm{PBS}(\mathrm{pH}$ $7 \cdot 4$ ) by incubation overnight at $4^{\circ} \mathrm{C}$. After discarding the cardiolipin solution $250 \mu \mathrm{l}$ of PBS with $10 \%$ fetal calf serum (FCS) was added to each well and incubated for two hours at room temperature to block non-specific binding of immunoglobulins to the well surface. After five washes with $0.05 \%$ Tween-20 in PBS $50 \mu \mathrm{l}$ of serum which were to be tested (diluted to $1 / 50$ with $\mathrm{PBS}$ containing $0.05 \%$ Tween-20 and $10 \%$ FCS) were added to each well and incubated for two hours at room temperature. After five washes with PBS $100 \mu$ l of alkaline phosphatase-labelled mouse monoclonal antihuman IgG (Miles, Naperville, Illinois, USA) was added to each well, and the plate was incubated for one hour at room temperature, followed by the addition of $100 \mu$ l of $p$-nitrophenyl phosphate (Sigma) in $1 \mathrm{M}$ diethanolamine buffer ( $\mathrm{pH} \mathrm{9.8).} \mathrm{After} \mathrm{incubation} \mathrm{for} 30$ minutes the optical absorbance was measured at $405 \mathrm{~nm}$ by Easy Reader (Laboscience, Tokyo, Japan). The values of IgG anticardiolipin antibodies were expressed as units compared with those of the standard serum. A positive result indicated a value in units more than 3 SD over the mean value obtained with control sera (106 healthy volunteers). 


\section{LUPUS ANTICOAGULANT}

The lupus anticoagulant was detected by the prolongation of activated partial thromboplastin time (APTT) in a mixing test, using the 1/5 diluted APTT reagent (Automated APTT, General Diagnostics, New Jersey, USA), which was based on the methods of Colaco et al, ${ }^{4}$ with a minor modification. When the APTT of a patient's plasma was prolonged over 10 seconds by mixing test with normal pooled plasma, the plasma was considered to be positive for lupus anticoagulant.

Titres of dsDNA antibodies were measured in the sera of the patients with SLE by radioimmunoassay using ${ }^{125} \mathrm{I}-\mathrm{DNA}$ radioimmunoassay kits supplied by Amersham International Ltd., England. ${ }^{18}$

Statistical analyses were carried out using Student's $t$ test and the $\chi^{2}$ test with Yates's correction. $p$ Values of less than 0.05 were regarded as significant.

\section{Results}

LONGITUDINAL STUDY OF IgG ANTICARDIOLIPIN ANTIBODIES

IgG anticardiolipin antibodies were detected in $69(44.5 \%)$ serum samples from 155 patients with SLE. Of 69 patients positive for IgG anticardiolipin antibodies, 43 were in the active, and 26 in the stable phases; and of the remaining 86 patients negative for IgG anticardiolipin antibodies, 37 were in active and 49 in stable phases. In 68 patients with detectable IgG anticardiolipin antibodies serum samples taken on at least at two separate occasions were assayed for IgG anticardiolipin antibodies. Longitudinal assays for IgG anticardiolipin antibodies enabled patients to be divided into two groups (figure). Group A comprised 39 patients who were persistently positive for IgG anticardiolipin antibodies at stable as well as active phases of SLE, and group B comprised 29

Serial measurement of IgG anticardiolipin antibodies in groups $A$ and $B$. Hatched area represents normal range of Ig $G$ anticardiolipin antibodies (mean $\pm 3 S D$ of the value in 106 healthy volunteers). Open circles indicate IgG anticardiolipin antibody titres at the first point out of two or more points during stable phases only, all of which were above normal.

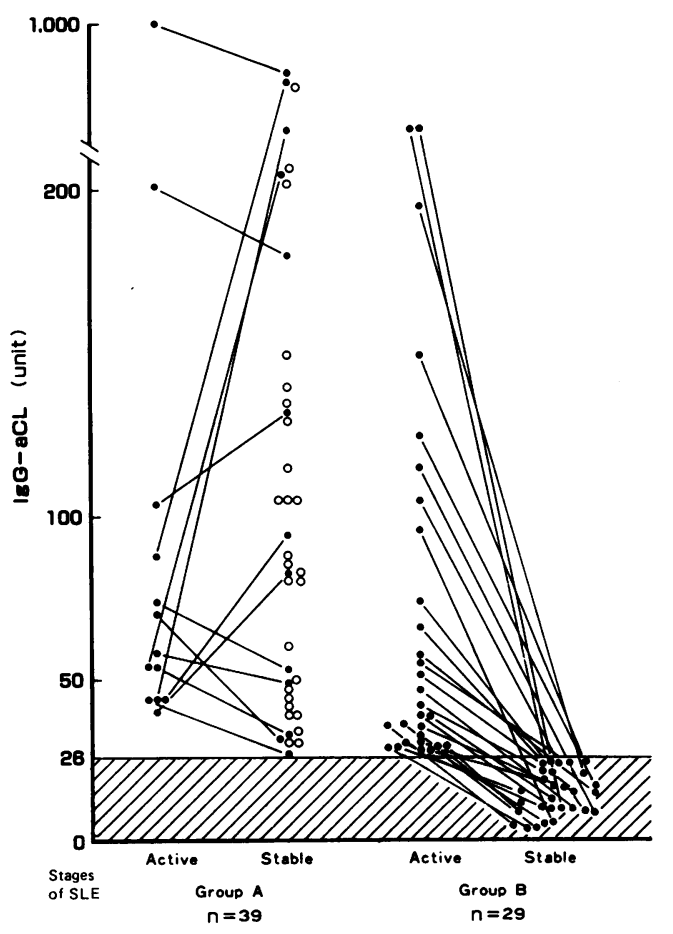

patients who were transiently positive for IgG anticardiolipin antibodies only during active phases. The mean period of observation was 24.7 and 26.5 months in groups $A$ and $B$, respectively.

In group A IgG anticardiolipin antibody titres increased in six and decreased in seven patients, but remained abnormally high during stable phases. There were no serum samples available during active stages from the 26 patients. As the titres of these patients never fell to within a normal range at subsequent points (data not shown), the 26 patients were placed in group A. In group B IgG anticardiolipin antibody titres fell to within a normal range in all 29 patients during stable phases.

\section{PATIENT CHARACTERISTICS IN BOTH GROUPS}

(table 1)

Sex ratio was similar between both groups. The mean ages of the patients in the two groups at the time of diagnosis of SLE was also similar-32.2 and 31.0 years in groups $A$ and $B$, respectively.

The mean titre of $\operatorname{IgG}$ anticardiolipin antibodies in group A was $141 \cdot 1$ units, significantly higher than the $82 \cdot 2$ units in group B during active phases $(p<0 \cdot 05)$. Although there was no significant difference between the two groups with regard to the initial dose of prednisolone, immunosuppressants (cyclophosphamide or azathioprine) were used more often in group B than in group $A(p<0.01)$. Of the 17 patients in group B who were given immunosuppressants, 10 had nephrotic syndrome, and in the remaining seven patients drugs were used for other manifestations of SLE, including central nervous system (CNS) lupus, thrombocytopenia, and severe vasculitis. On the other hand, of eight patients in group A who were given immunosuppressants, three had idiopathic thrombocytopenic purpura, two had renal disease, one had nephrotic syndrome, one had CNS lupus and one had severe vasculitis.

CLINICAL AND LABORATORY FEATURES IN BOTH GROUPS (table 2)

In an attempt to characterise the IgG anticardiolipin antibody positive patients clinical and laboratory features associated with SLE were compared between groups A and B (table 2). There was no difference between the two groups with regard to leucopenia, thrombocytopenia, CNS disease, hypertension, aseptic necrosis of bone (ANB) or Raynaud's phenomenon. Interestingly, pulmonary hypertension and a history of idiopathic thrombocytopenic purpura (ITP) were present only in group $A$,

Table 1: Patient characteristics

\begin{tabular}{lcc}
\hline & $\begin{array}{l}\text { Group } A \\
(n=39)\end{array}$ & $\begin{array}{l}\text { Group } B \\
(n=29)\end{array}$ \\
\hline Sex M & 3 & 4 \\
F & 36 & 25 \\
Age at diagnosis of SLE (years) & $32 \cdot 2$ & $31 \cdot 0$ \\
IgG anticardiolipin antibodies (unit) & $141 \cdot 1$ & $82 \cdot 2$ \\
Initial dose of prednisolone (mg/day) & $38 \cdot 9$ & $40 \cdot 9$ \\
Immunosuppressants & 8 & $17 \dagger$ \\
\hline " $<<0.05 ;$ tp $<0.01$.
\end{tabular}


Table 2: Comparison of clinical and laboratory features in both groups

\begin{tabular}{lcc}
\hline & $\begin{array}{c}\text { Group } A \\
n=39(\%)\end{array}$ & $\begin{array}{c}\text { Group } B \\
n=29(\%)\end{array}$ \\
\hline Leucopenia & $28(72)$ & $21(72)$ \\
Thrombocytopenia & $17(44)$ & $14(48)$ \\
Thromboses & $13(33) \dagger$ & $1(3)$ \\
Cerebral infarction & $9(23)^{*}$ & $1(3)$ \\
CNS disease & $5(13)$ & $3(10)$ \\
Renal disease & $17(44)^{*}$ & $21(72)$ \\
Nephrotic syndrome & $1(3) \dagger$ & $10(34)$ \\
Hypertension & $14(36)$ & $8(28)$ \\
Pulmonary hypertension & $2(5)$ & $0(0)$ \\
Aseptic necrosis of bone & $5(13)$ & $3(10)$ \\
Raynaud's phenomenon & $23(59)$ & $15(50)$ \\
History of ITP & $5(13)$ & $0(0)$ \\
Lupus anticoagulant & $15(45) \dagger$ & $2(8)$ \\
& $(n=33)$ & $(n=25)$ \\
Spontaneous abortion & $12(41)^{*}$ & $1(7)$ \\
& $(n=29)$ & $(n=14)$ \\
\hline
\end{tabular}

CNS = central nervous system; ITP = idiopathic thrombocytopenic purpura.

${ }_{\mathrm{p}}^{\mathrm{p}}<0.05, \mathrm{tp}<0.01$.

although no significant difference was found between the groups.

In contrast, however, the patients in group $\mathrm{A}$ differed from those in group B with regard to some clinical and serological aspects. Renal disease and nephrotic syndrome in group $A$ were rare $(p<0.05$ and $p<0.01$, respectively). The incidence of thromboses (arterial or venous, or both) was $33 \%$ (13 of 39 ) in group $A$, strikingly higher than the $3 \%$ (one of 29 ) in group $B(p<0.01)$. Moreover, cerebral infarction, which was included in the diagnosis of thromboses, was seen in nine of $39(23 \%)$ patients in group A, and in only one of $29(3 \%)$ patients in group B $(p<0.05)$. Twelve of 29 $(41 \%)$ married patients in group $A$ had experienced one or more spontaneous abortions, the incidence of which was significantly higher than that in group $B(7 \%)(p<0.05)$. It is thought that there is a close association between the presence of lupus anticoagulant and anticardiolipin antibodies. As predicted, the prevalence of lupus anticoagulant was much higher in group A than in group $B(p<0.01)$.

The response of SLE to corticosteroids or immunosuppressants, or both was equally favourable in both groups.

OBSTETRIC HISTORY IN BOTH GROUPS (table 3) To investigate further the association between the presence of IgG anticardiolipin antibodies and obstetric history, we selected 29 married patients from group A and 14 from group B. The number of pregnancies was 81 overall, $2 \cdot 8$ for each patient in group A and $26(1.9)$ in group B. The patients in group A seemed to have had more chances of pregnancy than those in group B, but no significant difference was found. When planned abortions were excluded

Table 3: Obstetric history of both groups

\begin{tabular}{|c|c|c|}
\hline & $\begin{array}{l}\text { Group } A \\
(n=29)\end{array}$ & $\begin{array}{l}\text { Group B } \\
(n=I 4)\end{array}$ \\
\hline $\begin{array}{l}\text { Total pregnancies } \\
\text { Planned abortions } \\
(\mathrm{T}) \\
(\mathrm{T})-(\mathrm{A}) \\
\text { Live births } \\
\text { Stillbirths } \\
\text { Spontaneous abortions }\end{array}$ & $\begin{array}{l}81(2 \cdot 8 / \mathrm{p}) \\
19(23 \%) \\
62 \\
40(64 \%)^{*} \\
1(2 \%) \\
21(34 \%)\end{array}$ & $\begin{array}{c}26(1 \cdot 9 / \mathrm{p}) \\
9(35 \%) \\
17 \\
16(94 \%) \\
0(0 \%) \\
1 \quad(6 \%)\end{array}$ \\
\hline
\end{tabular}

Table 4: ARA criteria in both groups

\begin{tabular}{lcc}
\hline 1982 ARA criteria & $\begin{array}{c}\text { Group } A \\
(n=39)(\%)\end{array}$ & $\begin{array}{c}\text { Group } B \\
(n=29)(\%)\end{array}$ \\
\hline 1 Malar rash & $29(74)$ & $24(83)$ \\
2 Discoid rash & $5(13)$ & $3(10)$ \\
3 Photosensitivity & $22(56)$ & $12(41)$ \\
4 Oral ulcers & $9(23)$ & $6(21)$ \\
5 Arthritis & $31(79)$ & $22(76)$ \\
6 Serositis & $12(31)$ & $11(38)$ \\
7 Renal disorder & $17(44)$ & $21(72) \dagger$ \\
8 Neurological disorder & $5(13)$ & $3(11)$ \\
9 Haematological disorder & $34(87)$ & $27(93)$ \\
$\quad$ Haemolytic anaemia & $11(28)$ & $12(43)$ \\
$\quad$ Leucopenia & $28(72)$ & $21(72)$ \\
$\quad$ Thrombocytopenia & $17(44)$ & $14(48)$ \\
10 Immunological disorder & $35(90)$ & $28(97)$ \\
$\quad$ Lupus erythematosus cell & $13(36)$ & $14(52)$ \\
$\quad$ Anti-dsDNA & $28(72)$ & $28(97)$ \\
$\quad$ Anti-Sm & $6(16)$ & $3(11)$ \\
$\quad$ False positive serological & $15(38)$ & $14(48)$ \\
$\quad$ test for syphilis & $38(97)$ & $29(100)$ \\
11 Antinuclear antibody & & $6.5 \pm 0.5$ \\
Numbers of ARA criteria & $6.0 \pm 0.3$ & 6 \\
\hline${ }^{*}$ p<0.05, tp<0.01. & &
\end{tabular}

from the number of pregnancies, the percentage of live births was $65 \%$ ( 40 of 62 ) in group $A$ and $94 \%(16$ of 17$)$ in group $B(p<0.05)$. It should be emphasised that the incidence of spontaneous abortion in group A was significantly higher $(34 \%, 21$ of 62$)$ than that in group $B(6 \%$, one of 17) $(\mathrm{p}<0.05)$.

Each ARA criterion for SLE was compared in both groups (table 4). Renal disorders and positivity for anti-dsDNA antibodies were less common in group A than in group B. Other variables were similar for both groups.

\section{Discussion}

Anticardiolipin antibodies, which are often found in patients with autoimmune diseases including SLE, have attracted considerable attention because of their possible association with vascular thromboses and repeated spontaneous abortions. Recent investigations have shown that anticardiolipin antibodies are found in about $40 \%$ patients with SLE, ranging from 23 to $82 \% .^{11} 131719-22$ We found IgG anticardiolipin antibodies in the serum samples of 69 of $155(44.5 \%)$ patients and our results were compatible with those of other reports.

Our serial measurements of IgG anticardiolipin antibodies in patients with SLE showed two distinct subgroups: group A patients who were persistently positive for IgG anticardiolipin antibodies during active and stable phases of SLE; group B patients who were positive for IgG anticardiolipin antibodies only during active phases. We found apparent differences in the clinical features of both groups. Vascular thromboses, including cerebral infarction and spontaneous abortions, occurred more often in group A; the incidence of these was very low in group $B$. These results suggest that patients with SLE who persistently possess IgG anticardiolipin antibodies, irrespective of disease activity and treatment, are at risk of thromboses and spontaneous abortions.

The presence of anti-dsDNA antibodies and renal disease are important markers of disease activity in SLE. Our results showed that the incidence of renal disease including nephrotic syndrome and the incidence of anti-dsDNA 
antibodies were significantly lower in group $\mathbf{A}$ than in group B, suggesting that group $\mathbf{A}$ tended to have milder SLE disease activity than group $B$. The association between IgG anticardiolipin antibodies and renal disease in SLE is still controversial. McHugh et al suggested that IgG anticardiolipin antibodies were associated with renal diseases. ${ }^{22}$ On the contrary, Weidmann et al mentioned that antiphospholipid antibodies had an inverse association with renal disease and suggested that this reflected a possible decrease in the antiphospholipid antibody titres as a result of treatment with immunosuppressants. ${ }^{27}$ These investigators, however, did not group the patients in terms of the persistence of anticardiolipin antibodies, and a direct comparison with our results may be difficult.

There was no difference in the initial dose of corticosteroids between groups A and B. This indicates that IgG anticardiolipin antibodies could not be reduced by treatment with corticosteroids in the patients in group A. Derkson et al showed that the effect of steroids on the anticardiolipin antibody titre was quite unpredictable whereas they could decrease lupus anticoagulant activity. ${ }^{14}$ On the other hand, our study showed that immunosuppressants were more often used for the patients in group B. This may have reflected the fact that the prevalence of renal diseases including nephrotic syndrome in group B was higher than in group A. Immunosuppressants may also lower IgG anticardiolipin antibodies. IgG anticardiolipin antibodies in group A tended not to respond to immunotherapy despite milder disease activity. By contrast, IgG anticardiolipin antibodies in patients in group $B$, who had more active SLE, seemed to decrease rather easily in response to corticosteroids or immunosuppressants, or both. Simel stated that immunosuppressants were probably of limited value in reducing antiphospholipid antibody titres. ${ }^{15}$ On the other hand, Harris et al suggested that the anticardiolipin antibody titres might parallel disease activity and that treatment with immunosuppressants might lower anticardiolipin antibody titres. ${ }^{13}$ Our results may bridge this discrepancy in that there are two subgroups of patients with SLE in whom immunosuppressants can (group B) and cannot (group A) lower IgG anticardiolipin antibody titres.

The prevention and treatment of vascular thromboses and spontaneous abortions in patients with anticardiolipin antibodies is of great concern, ${ }^{13}$ but still remains to be established. Our results show that for the prevention of thromboses and spontaneous abortions no special treatment other than that for SLE seems to be needed for the patients in whom IgG anticardiolipin antibodies are detected only during the active phases of SLE and disappear in conjunction with the decrease in disease activity (group B). We propose that those patients (group A) who have a history of vascular thromboses and spontaneous abortions should be treated with prolonged anticoagulant drugs, and possibly, with anti-platelet drugs.

In conclusion, this study has disclosed that there is a subset of patients with SLE who persistently have IgG anticardiolipin antibodies, irrespective of their disease activity, and who are at a risk of vascular thromboses and obstetric disorders. Moreover, this subset of patients has a rather mild SLE disease activity and we believe that the term 'anticardiolipin syndrome' should be attributed to such patients.

We thank Ms K Miller for comments on the manuscript. This work was in part supported by Grant-in-Aid for the Research of Autoimmune Diseases by the Ministry of Welfare, Japan.

1 Harris E N, Gharavi A E, Boey M L, et al. Anticardiolipin antibodies: detection by radioimmunoassay and association with thrombosis in systemic lupus erythematosus. Lancet 1983; ii: 1211-14.

2 Boey M L, Colaco C B, Gharavi A E, Elkon K E, Loizou S, Hughes G R V. Thrombosis in systemic lupus erytheHughes G R V. Thrombosis in systemic lupus erythematosus: striking association with the presence of circulat
ing lupus anticoagulant. $\mathrm{Br} \mathrm{Med} \mathcal{F}$ 1983; 287: 1021-3.

3 Lockshin M D, Druzin M L, Goei S, et al. Antibody to cardiolipin as a predictor of fetal distress or death in pregnant patients with systemic lupus erythematosus. $N$ Engl F Med 1985; 313: 152-6.

4 Colaco C B, Elkon K B. The lupus anticoagulant: a disease marker in antinuclear antibody negative lupus that is crossreactive with autoantibodies to double-stranded DNA. Arthritis Rheum 1985; 28: 67-74.

5 Derue G J, Englert H J, Harris E N, et al. Fetal loss in systemic lupus: association with anticardiolipin antibodies. systemic lupus: association with

6 Glueck H I, Kant K S, Weiss M A, Pollak V E, Miller M A, Coots $M$. Thrombosis in systemic lupus erythematosus: Coots $M$. Thrombosis in systemic lupus erythematosus:
relation to the presence of circulating anticoagulants. Arch relation to the presence of circu
Intern Med 1985; 145: 1389-95.

7 Mayumi T, Nagasawa K, Yamauchi Y, et al. A clinical study on lupus anticoagulant in systemic lupus erythematosus. fapanese fournal of Clinical Immunology 1987; 10: 78-84.

8 Cronin M E, Biswas R M, Van der Straeton C, Fleisher T A, Klippel J H. IgG and IgM anticardiolipin antibodies in patients with lupus with anticoagulant antibody associated clinical syndromes. I R heumatol 1988; 15: 795-8.

9 Harris E N, Chan J K H, Asherson R A, Aber V R, Gharavi A E, Hughes G R V. Thrombosis, recurrent fetal loss, and thrombocytopenia: predictive value of the anticardiolipin thrombocytopenia: predictive value of the anticardic
antibody test. Arch Intern Med 1986; 146: 2153-6.

10 Anonymous. The anticardiolipin syndrome. [Editorial]. Anonymous. The anticardiolipin
f Rheumatol 1986; 13: 486-9.

11 Sturfelt G, Nived O, Norverg R, Thorstensson R, Krook K. Anticardiolipin antibodies in patients with systemic lupus erythematosus. Arthritis Rheum 1987; 30: 382-8.

12 Kalunian K, Peter J B, Middlekauff H R, et al. Clinical significance of a single test for anti-cardiolipin antibodies in patients with systemic lupus erythematosus. $A m \mathcal{F}$ Med 1988; 85: 602-8.

13 Harris E N, Gharavi A E, Hughes G R V. Anti-phospholipid antibodies. Clin Rheum Dis 1985; 11: 591-609.

14 Derkson $R$ W $M$, Biesma D, Bouma B N, Meyling $F$ H J G, Kater $L$. Discordant effects of prednisone on $F$ H J G, Kater L. Discordant effects of prednisone on
anticardiolipin antibodies and the lupus anticoagulant. anticardiolipin antibodies and the
Arthritis Rheum 1986; 29: 1295-6.

15 Simel D L, St Clair E W, Adams J, Greenberg C S. Correction of hypoprothrombinemia by immunosuppressive treatment of the lupus anticoagulant-hypoprothrombinemia syndrome. Am $\mathcal{Y}$ Med 1987; 83: 563-6.

16 Tan E M, Cohen A S, Fries J F, et al. The 1982 revised criteria for the classification of systemic lupus erythematosus. Arthritis Rheum 1982; 25: 1271-7.

17 Koike T, Sueishi M, Funaki H, Tomioka H, Yoshida S. Anticardiolipin antibodies and biological false positive serological test for syphilis in patients with systemic lupus serological test for syphilis in patients with system

18 Clarke M C, Carr R, Burdash N M, Chen Z, Ainsworth S K. A comparison of three anti-double stranded DNA antibody assays on sera from SLE and other diseases. Diagn Immunol 1986; 4: 288-93.

19 Colaco C B, Male D K. Anti-phospholipid antibodies in syphilis and a thrombotic subset of SLE: distinct profiles of epitope specificity. Clin Exp Immunol 1985; 59: 449-56.

20 Loizou S, McCrea J D, Rudge A C, Reynolds R, Boyle C C, Harris E N. Measurement of anti-cardiolipin antibodies by an enzyme-linked immunosorbent assay (ELISA): standardization and quantitation of results. Clin Exp Immunol 1985; 62: $738-45$

21 Fort J G, Cowchock F S, Abruzzo J L, Smith J B. Anticardiolipin antibodies in patients with rheumatic diseases. Arthritis Rheum 1987; 30: 752-60.

22 McHugh N J, Maymo J, Skinner R P, James I, Maddison P J. Anticardiolipin antibodies, livedo reticularis, and major matosus. Ann Rheum Dis 1988; 47: 110-15.

23 Weidmann C E, Wallace D J, Peter J B, Knight P J, Bear M B, Klinenberg J R. Studies of IgG, IgM and IgA $M$ B, Klinenberg J R. Studies of IgG, IgM and $\operatorname{IgA}$
antiphospholipid antibody isotopes in systemic lupus eryantiphospholipid antibody isotopes in sys 